\title{
TRANSFORMING METAL INTO SKIN
}

\author{
EUGENIE KEEFER BELL
}

School of Design and Architecture

University of Canberra

Canberra, ACT 2601, Australia

Eugenie.keefer.bell@canberra.edu.au

\begin{abstract}
Frank Gehry's 1997 Guggenheim Museum Bilbao drew international attention to the physical and rhetorical potential of titanium for use as a building 'skin.' Titanium was transformed from a material previously associated with the aerospace, medical and jewellery industries into a signifier of architectural eloquence. Metal and metal-clad buildings have a largely functionalist history in architecture of the past century; some are intentionally severe, while others result from necessity occasioned by poverty. Less commonly, they are the work of architects including Gehry, Kisho Kurakawa and Daniel Libeskind using metals such as titanium for their physical and narrative possibilities. This paper examines the extended possibilities of the metal-clad building through the tectonic and metaphoric use of titanium, set in the context of the historic uses and symbolism of metal in architecture. Titanium is one of the most common elements in the earth's crust. It is assertively resistant; to heat, to electrical current, to decay, and to the metal working techniques common to most other metals. In architectural application, it is a postindustrial material that challenges the traditional hierarchy of material use. In the hands of architects such as Gehry, Kurakawa and Libeskind, the titanium skin becomes a medium for poetic transformation of architectural form.
\end{abstract}

Keywords: Titanium, architectural skin, architectural metal, Frank Gehry.

\section{Transforming metal into skin}

This paper examines the metal-clad building through the tectonic and metaphoric use of titanium, set in the context of historic uses and symbolism of metal in architecture.

Frank Gehry's 1997 Guggenheim Museum Bilbao spectacularly demonstrated titanium's potential as a building's 'skin.' Bilbao's 'quilted' titanium wrapping drew international attention to the physical and rhetorical potential of the metal, transforming a post-industrial material previously more readily associated with aerospace, medical and jewellery industries into a signifier of architectural eloquence. In the following decade, other architects adopted titanium as a material appropriate for twenty-first century architecture. In 1999, for example, Kisho Kurakawa, sheathed his eloquently gestural addition to the Van Gogh Museum in Amsterdam with matt-finished titanium. ${ }^{1}$ More recently opened in 2006, Daniel Libeskind employed titanium cladding in his first completed building in North America, the Frederic C. Hamilton Building extension to Colorado's Denver Art Museum. ${ }^{2}$ These and other late- $20^{\text {th }} / \mathrm{early}-21^{\text {st }}$ century buildings reply upon the language of metal as a building's 'skin' or covering 'fabric,' while 
reinterpreting the traditional hierarchy of material use. Since Bilbao, and accompanied by its increasing affordability, titanium has been successfully promoted as a 'material of the $21^{\text {st }}$ century.'

\section{$2 \quad$ Skin and bones}

Discussion of the language of building cladding or skin has a long history, especially since its consideration in the context of material and materiality by German architect Gottfried Semper in the mid-nineteenth century, and his advocacy of 'dressing' (Bekiedung) ${ }^{3}$ as foundational to understanding the origins of architecture. ${ }^{4}$ In Der Stil, published in 1863, Semper included an important discussion of the "four elements" of architecture based on his observations of a Caribbean hut displayed in London at the Great Exhibition of 1851. Harry Francis Mallgrave, in Gottfried Semper: Architect of the Nineteenth Century, describes Semper's encounter with the "Caraib hut" [sic] as the "simple habitat [which] exemplified for him perfectly his 'four elements' of architecture in their prototypical form" (198). ${ }^{5}$ These individually distinguishable elements, the mound or platform, a tectonic framework supporting the roof, and the woven walls hung between the roof supports, comprised the archetypal architectural form for Semper (Mallgrave 197-199). ${ }^{6}$ They represented a 'return to origins,' as for Vitruvius in the first century, a return to authentic order. The 'skin and bones' of Bilboa has resonance with Semper's allusions to weaving, and dressing, especially where the 'woven' substructure which supports the thin 'quilted' titanium cladding is seen in construction images. Semper's discourse on structure (load bearing), cladding and dressing was continued by others through the nineteenth century, including in 1898, Adolf Loos' "Law of Dressing" (Gesetz der Bekleidung). ${ }^{7}$ Otto Wagner, in his guide book for students, Modern Architecture, emphasized the evolution of the "basic forms of supports, walls and rafters to art-forms [Kunstformen]," which suggests craft forms such as carpets or tapestries (93). ${ }^{8}$

Through the twentieth and early twentieth centuries, building skin possibilities expanded exponentially with the emergence of advanced materials and technologies. Continuing the model established in Joseph Paxton's Crystal Palace for the Great Exhibition of 1851, subsequent international expositions through the twentieth century provided a setting for architectural experimentation in materials and form. At Expo '67 in Montreal, for example, Frei Otto and Rolf Gutbrod's German pavilion was noted for its spectacular steel cable, 'woven' tensile mesh structure, and translucent skin (Mattie 232-233). At Expo '70 in Osaka, ${ }^{9}$ The USA Pavilion, designed by architects Davis, Brody, Chermayeff, Geismar and de Harak Associates, was a $142 \times 83.5$ metre super-elliptical structure consisting of a shallow pneumatic skin of white fibreglass-coated vinyl over a grid of steel cables. The 29 April 1970 Architect's Journal declared it "the most significant new structural technique at Expo" (1064). Thirty years later, as Christian Schittich observed, the 2000 Expo in Hanover was a "fair for skin materials, a trade fair for contemporary potentials," noting the Finnish pavilion's glass skin, and the Iceland pavilion's membrane structure, where water flowed on all sides (21). Such exemplars set the aesthetic and metaphoric understanding of titanium in the context of late Modernism's penchant for 'transparency.' 10

Titanium - named for the Greek god, Titus - is one of the most common elements in the earth's crust. Though identified as an element by the $18^{\text {th }}$ century, efficient extraction technologies for titanium, and its sister refractory metals tantalum and niobium, were not developed until the $20^{\text {th }}$ century. In metal form, titanium is highly refractory, strong and corrosion resistant. Low specific gravity and resistance to heat conduction facilitates its extensive use in aerospace rockets, as well as in the construction of jet fuselages and engines. Titanium is used for replacement heart valves which require a light weight, biocompatible material that remains inert in bodily fluids. The metal's working properties are limited by the technical difficulty of processes such as welding, such that larger-scale sheet use in aerospace or architecture is usually in coldconnected form. Its capacity to be decoratively treated with interference colouring (a process later described in this paper) was initially explored by jewellers, especially in the 1970s and 1980s.

This adoption of titanium into the lexicon of contemporary architecture participates in a complex history of the functional uses and symbolic social value of metal. Metal and metal-clad buildings, for example, have a largely functionalist history in the architecture of the past century. Some, such as structurally economical Quonset or Nissen huts, or transportable buildings destined for scientific use in extreme climates, were intentionally severe. Others resulted from necessity occasioned by varying degrees of poverty. Less commonly, metal or metal-clad buildings are the work of architects using a particular metal for its physical and narrative 
possibilities and through that process re-negotiating, or transforming, the material's relative status. Notable exemplars include Buckminster Fuller's c.1949 aluminium-clad Dymaxion house, and Frei Otto and Gunter Behnisch's spectacular steel cable net and polyester fabric 'tents' for the 1972 Munich Olympics, and more recently the work of Glenn Murcutt.

Application of metals, including titanium, aluminium and steel, as finish or cladding in twentieth and twenty-first century architecture is set within the larger history of the functional and decorative uses of metal in architecture and the emblematic roles of metal in society. Metals play a central role in most civilizations, such that ancient cultures were in part defined by the metals that they processed and used for vessels, weapons and for ritual, as in the bronze age and the copper age. Until the $17^{\text {th }}$ century, the functional role of metal in architecture was predominantly that of joining, as in hinges, locks, strapping, fastenings and nails. As such, metal both symbolised and bore an essential role in the fabrication of buildings, marking the place where one material met and supported another. It was traditionally celebrated in doors, where its expense and refinement could be appreciated, and its values celebrated. Elsewhere, architectural metal defined a physical condition of boundary, as exclusion, forced enclosure, or barricade, as in the bars of prisons, or treasuries. Metal used as finish or as cladding of a roof or walls has another history, linked to but partially distinct from its use as a joining element or structural component. Like metal in the larger setting of society, metal in architecture participates in an extended discourse of value and of symbol. Gehry's, Kurakawa's and Libeskind's use of titanium 'skins' is necessarily situated within this broader historical context.

It is a truism to say that gold is commonly held to be the standard bearer of value for metals. From the ancient world, where knowledge of gold working was highly developed, gold artefacts are comparatively plentiful. Etruscan vessels made from electrum, a naturally occurring alloy of gold and silver, have occasionally been found in the Tuscan region of Italy. Pure silver objects, however, are exceptionally rare, as large silver deposits had not then been discovered. While symbolically and metaphorically gold is historically pre-eminent, in monetary terms other metals have borne similar or even greater relative value. In each case, such value reflects comparative rarity, the difficulty of extracting the particular ore, the technical challenges of alloying or working or a combination of such factors. This is in contemporary times the case with the precious metal platinum, with certain rare ores, and historically the case with other metals, including aluminium and titanium.

During the European Industrial Revolution in the $18^{\text {th }}$ century, metal took on greater structural, architectonic roles, as the technologies of iron and steel working rapidly developed. The imperative to transport increasing numbers goods and people resulting from the twin factors of industrialization and urbanization gave impetus to development of bridges and railway stations where metal became the predominant structural material. In 1778-79, Coalbrookdale Bridge (designed by Abraham Darby III and Thomas F. Pritchard) became the first cast iron frame bridge, constructed over the Severn River at the site of an ironworks dating from the late $17^{\text {th }}$ century. An immediate success, it was followed by other celebrated 'marvels' of engineering. Many endured, including the graceful Clifton Suspension Bridge over Avon Gorge, Bristol, designed in 1830 and begun by Isamabard Kingdom Brunel, is still in daily use. Improved metal casting techniques soon facilitated development of wide span construction in railway stations including in 1854 the New Street Station in Birmingham and the second Paddington Station in London. Railway station facades, however, remained aligned with more 'classical' notions of appropriate public space.

The use of metal for structural skeletons of buildings was established by the first half of the nineteenth century, especially in the design of winter gardens and conservatories. Here the inventive structures of Joseph Paxton came to the fore. Though not the first to design a 'glasshouse,' Paxton improved the conservatory type in greenhouses through the use of iron structures while maintaining wooden substructures for the glazing. In the 1836 Chatsworth greenhouse in Devonshire, Paxton developed the structural language that would be employed in his design for the Crystal Palace in 1850. ${ }^{11}$ In Paxton's buildings, like other mid-19 ${ }^{\text {th }}$ century exemplars such as Burton's 1845 Palm House at Kew Gardens, iron frames were entirely clad with glass supported in light wooden frames. While the modular structural framing was admired, especially in the Crystal Palace, it was the glass that particularly excited the public fear and imagination. The material of glass and its allegories of transparency subsequently became powerfully emblematic of twentieth century architecture in the work of Mies van der Rohe and others. 
The history of aluminium's transformation into an architectural cladding material provides an example comparable to that of titanium. Prior to development of modern smelting and mass manufacturing techniques, the monetary value of aluminium in the $19^{\text {th }}$ century was analogous to gold. In the Paris International Exhibition of 1885, for example, a bar of aluminium was displayed as a wonder of the modern age. When refining and manufacturing capabilities expanded in the $20^{\text {th }}$ century, aluminium became used increasingly in domestic artefacts such as jewellery and furniture, then was put to service in the developing automotive and airplane industries, and in architecture, where its role was both functional and symbolic. ${ }^{12}$

In the 1930s, aluminium was dramatically used to sheath the top of the Chrysler Building in New York City. Crowned with a thrusting spire and powerful aluminium bald eagles functioning as did water spouts on gothic cathedrals, the Chrysler Building epitomized the optimism, expansiveness and industrial modernity of the United States. Images such as Margaret BourkeWhite's 1938 photographs of the aluminium-clad, eagle-headed zenith offered powerful confirmation of such beliefs. The time of the Chrysler Building also coincides with the rapid increase in advertising in the press and in the expanding audio media in the United States. Where in earlier centuries sacred architecture served as a city's identifying marker, by the 1930s, edifices such as the Chrysler Building establish a new decorum, becoming advocates for a new status of architecture, and for the status of a city.

The use of aluminium in the Chrysler Building reiterates another historic use of metal in building, that of value signifier where used as a spire or roofing material. Gold, in leaf or fused tile form, was naturally the supreme material with which to sheath the apex of a usually sacred building. Occasionally gold was used even more lavishly, as on the Shwedagon Pagoda complex in Myanmar, and on Kinkakuji (Golden temple) in Kyoto. Elsewhere, the gilded laurel leaf dome of the secular Secession building in Vienna deliberately alludes to this tradition in metals. Cladding a roof or spire with a less noble but still costly metal such as copper was in the nineteenth and twentieth centuries comparatively ubiquitous, such that copper roof tiles on houses are widely found in the United States and in Europe, but only on the homes of the wealthy. Titanium architectural skins have in the past decade articulated a parallel material 'language,' especially where used to signify a building as a 'destination' in itself, and as such to embody and convey the values and status of the city. Simple use, however, does not necessarily delight the eye, when the signage is adopted with insufficient exploration of its potential. This appears the case with the Cerritos Millennium Library in Los Angeles, which on its website claims for its 1999-2002 the distinction of being the first titanium clad building in the United States. ${ }^{13}$ The Library additions, undertaken by Charles Walton and Associates, who had completed an earlier award winning expansion in the 1980s, constitute a polite building. The 'sign' is present, but its articulation is rather prosaic.

In finishing treatments, titanium differs from other metals in its capacity for modification with optical interference colours. These are achieved through electrochemical deposition of surface oxide films, rather than by patination or by the use of metallic dye salts, as for aluminium. In brief summary, the surface of ferrous metals such as steel, and non-ferrous metals including copper, bronze and silver, are often chemically treated through patination to achieve a wide range of colours. ${ }^{14}$ Aluminium anodizing is an electro-chemical process through which a honeycomb surface of aluminium oxide is 'grown' in an sulphuric acid bath. The porous surface can be coloured with various metallic or organic dyestuffs, then sealed in a water or water/chemical bath. The anodizing process differs from the dyeing of textiles, for example, where colour is bonded with the fibre; in anodized aluminium, colour is effectively trapped within the cellular surface structure. In titanium, colour is achieved through utilization of the optical qualities of light refraction, resulting in 'apparent' or interference colour in the same sense as a film of oil on water appears to have colour. ${ }^{15}$ Titanium is especially receptive to interaction with oxygen, a property that can be accelerated by applying an electric current through an electrolyte solution to develop a transparent film on its surface. The film is fractions of a micron thick, leaving the substrate of the metal unchanged. Light travelling through the transparent film is refracted at angles dependent on the film's relative thickness, resulting in consistently predictable colours. ${ }^{16}$ The film can also be achieved through the application of heat, but the results are generally less controllable and the colour therefore variable.

These particular qualities of titanium permit the architectural use of colours such as rose and gold, as in Gehry's exuberant Marqués de Riscal Winery Hotel, built in Elciego in the Rioja region of Spain. However, while the substrate is stable, and the physical transparent film largely impervious to permanent change other than through abrasion, the apparent colour may be obscured by oil, dirt or other contaminants. In architectural application, this requires a kind of 
'white glove' handling of titanium sheet in installation, to minimize the transfer of skin oils to the film (Proctor). Post-installation 'staining' of the titanium at Bilbao was controversial in its early years, and was variously attributed to effects of atmospheric pollution and to inadequate postinstallation removal of residual sealants. Cleaning by mountaineers was planned (Wilkinson).

Gold, in its pure state, does not corrode or deteriorate: it is the alloy metals that leach out over time. Most other metals are less stable, depending on their environmental conditions: iron and most steel rusts, while copper and bronze shift from reds to greens and browns. Nonetheless, metal has a portent of resisting time. ${ }^{17}$ As with gold, the physical properties and the metaphor of temporal resistance are especially evident in the case of titanium, which remains inert in all but the most extreme environments. The intrinsic properties of corrosion resistance are such that at least one major distributor, Timet@, warrants its commercially pure architectural grade 1 titanium for one hundred years (Timet).

Titanium architectural skins further participate in metaphors of temporality through their responsiveness to the ambient qualities of light and shadow, reflecting in their surfaces the daily passage of time. While Gehry also uses stainless steel panels, as in the Walt Disney Concert Hall in Los Angeles, this chameleon-like effect of titanium is particularly evident in the jubilant sculptural forms of Bilbao and other of Gehry's titanium skins. It is more soberly expressed in the case of Kurakawa's elegant Van Gogh Museum and in Libeskind's addition to the Denver Art Gallery, where titanium clad 'crystal' forms reiterate or embody in the architecture the presence of the nearby mountains. In the hands of such architects, the titanium skin becomes a medium for poetic transformation of architectural form.

\section{$3 \quad$ Notes}

1 Kurokawa's 1999 building faces the Van Gogh Museum's original building, which was designed in 1963-64 by Gerrit Rietveld and completed in 1973 by Rietveld's partners after his death. See http://www3.vangoghmuseum.nl

${ }^{2}$ The 146,000 square foot Frederic C. Hamilton building, by Daniel Libeskind and Denver-based Davis Partnership Architects opened in October, 2006. It adjoins the Museum's North Building, designed by Gio Ponti in 1971. See Denver Art Museum Fact Sheet.

${ }^{3}$ See also Harry Francis Mallgrave and Wolfgang Hermann. Trans. Gottfried Semper: The Four Elements of Architecture and Other Writings. 102-106, 246-263.

${ }^{4}$ Semper was preceded in discourse on tectonics by Karl Friedrich Schinkel and Karl Bötticher. See Mitchell Schwarzer "Ontology and Representation in Karl Bötticher's Theory of Tectonics."

${ }^{5}$ See also Wolfgang Herrmann, "Semper's Position on the Primitive Hut," in Gottfried Semper: In Search of Architecture. 165-173.

${ }^{6}$ See also Joseph Rykwert, "Semper and the Conception of Style," in The Necessity of Artifice. 122-130.

${ }^{7}$ For discussion on Loos' "Law of Dressing," see Mark Wigley, White Walls, Designer Dresses: the Fashioning of Modern Architecture. 10-11.

${ }^{8}$ Wagner noted: "The first human form was the roof, the protective covering, surely a substitute for the lack of a cave. The roof preceded the supports, the wall, even the hearth. After the roof came the supports, artificially built of tree trunks, and stones, and finally the wickerwork, the partition, the bearing wall" (93). He advocated cladding in "a modern way of building [...using a panel system of...] nobler material [...] to be fastened with bronze bolts (rosettes)" (96). Though outside the scope of this paper, it is of note that Wager asserts his (Gesumtkunstwerk) belief in importance of the harmonious 'cladding' of a building's inhabitants: "The appearance and occupation of the inhabitant should harmonise with the appearance of the room" (118).

${ }^{9}$ For discussion of Expo '70, see Eugenie Keefer Bell, "Celebrating Equivalence: Expo '70 in Osaka, Japan."

${ }^{10}$ See Colin Rowe and Robert Slutzky, 'Transparency: Literal and Phenomenal (Part 2),' in Joan Ockman. Ed. Architecture and Culture 1943-1968. 206-225.

${ }^{11}$ For an engaging biography of Joseph Paxton, see Kate Colquhoun, A Thing in Disguise: The Visionary Life of Joseph Paxton. 
${ }^{12}$ For discussion of the history of aluminum, see Sarah Nichols, Aluminum by Design.

13 "As the Second and Third Floors of the [Cerritos] Library are future-oriented, the exterior of these levels were wrapped in a skin of titanium. The Library was the first titanium-clad structure in the United States. Titanium expresses the concept of change as it has subtle color shifts from reflecting the angle of the sun and atmospheric conditions. Titanium also allowed for a fluid design with compound curves. The material suggests the Library's "Save the Planet" theme as it does not have a negative impact on the environment and is maintenance free." http://www.ci.cerritos.ca.us/library/libhistory.html

${ }^{14}$ See Richard Hughes and Michael Rowe, The Colouring, Bronzing and Patination of Metals.

15 Titanium's 'sister' metals, tantalum and niobium, can be similarly treated. Their colours are more intense than titanium, but are less frequently used, due to their significantly greater cost.

${ }^{16}$ For a technical explanation of the small-scale colouring of titanium, see I.J. Keefer [Eugenie Keefer Bell], Spatial Narrations in Metal.

${ }^{17}$ For an evocative discussion on weathering, see Mohsen Mostafavi and David Leatherbarrow. On Weathering: The Life of Buildings in Time.

\section{$4 \quad$ References}

Bell, Eugenie Keefer. "Celebrating Equivalence: Expo '70 in Osaka, Japan." Celebration: XXII Annual Conference of the Society of Architectural Historians Australia and New Zealand. Ed. Andrew Leach and Gill Mathewson. Napier New Zealand: Society of Architectural Historians Australia and New Zealand (SAHANZ), 2005. 41-46.

Colquhoun, Kate. A Thing in Disguise: The Visionary Life of Joseph Paxton. London: Harper Perrenial, 2004.

Ceritos Library. 2 July 2007. http://www.ci.cerritos.ca.us/library/libhistory.html.

Denver Art Museum Fact Sheet. 2 May 2007. http://www.denver.artmusuem.org

Hermann, Wolfgang. Gottfried Semper: In Search of Architecture. Cambridge: MIT Press, 1984.

Hughes, Richard and Michael Rowe. The Colouring, Bronzing and Patination of Metals. London: British Crafts Council, 1986.

Keefer, I. J. (Eugenie Keefer Bell). Spatial Narrations in Metal. Masters thesis. San Diego: San Diego State University, 1979.

Mallgrave, Harry Francis and Wolfgang Hermann. Trans. Gottfried Semper: The Four Elements of Architecture and Other Writings. Cambridge: Cambridge University Press, 1989.

Mallgrave, Harry Francis. Gottfried Semper: Architect of the Nineteenth Century. New Haven and London: Yale University Press, 1996.

Mattie, Erik. World's Fairs. New York: Princeton Architectural Press, 1998.

Mostafavi, Mohsen and David Leatherbarrow. On Weathering: The Life of Buildings in Time. Cambridge, Massachusetts: The MIT Press, 1993.

Nichols, Sarah. Aluminum by Design. Pittsburgh: Carnegie Museum of Art, 2000.

Proctor, Don. "Challenging design places demands on installation." The Daily Commercial News Online $\quad 16 \quad$ Aug. $2007 . \quad$ http://www.dcnonl.com/cgibin/dcnhome.pl?rm=print story\&story id=20939

Rowe, Colin Rowe and Robert Slutzky. "Transparency: Literal and Phenomenal (Part 2)." Architecture and Culture 1943-1968. Ed. Joan Ockman. New York: Rizzoli, 1993. 206-225. Originally published in Perspecta: The Yale Architecture Journal 13/14 (1971): 286-301.

Rykwert, Joseph. The Necessity of Artifice New York, Rizzoli, 1982).

Schwarzer. Mitchell. "Ontology and Representation in Karl Bötticher's Theory of Tectonics." The Journal of the Society of Architectural Historians 52.3 (Sept., 1993): 267-280.

Shchittich, Christian. Building Skins: Concepts Layers, Materials. Munich: Birkhäuser, 2001.

Timet. 5 May 2007. http://www.timet.com/architecture/index.htm 
United States." The Architects' Journal 151.17 (29 April 1970): 1062-1064.

Van Gogh Museum. 2 May 2007. http://www3.vangoghmuseum.nl

Wagner, Otto. Modern Architecture. Los Angeles: The Getty Center, 1988.

Wigley, Mark. White Walls, Designer Dresses: the Fashioning of Modern Architecture. Cambridge, Mass. and London: The MIT Press, 1995.

Wilkinson, Isamabard. "Row with architect tarnishes image of Guggenheim." Telegraph $\begin{array}{llllll}\text { (London) } & 19 & \text { June } & 2001 . & 16 & \text { Aug. }\end{array}$ http://www.telegraph.co.uk/news/main.jht,?xml=/news/2001/01/11/wgugg11.xml 